\title{
Color Change of Esthetic Restorative Materials for Different Staining and Whitening Dentifrices
}

\author{
EunJung Choi ${ }^{1}$, HyeonSoo Jang ${ }^{2}$, YeLim Seo ${ }^{2}$, YoungJu Kim², GaYoung Lee ${ }^{2}$, YouLim Kim², \\ and Soo-Jeong Hwang ${ }^{3, \dagger}$ \\ 'Department of Optometry, Konyang University, Daejeon 35365, ${ }^{2}$ Department of Dental Hygiene, Konyang \\ University, Daejeon 35365, ${ }^{3}$ Department of Dentistry, Doonsan Health Promotion Center, Daejeon 35230, Korea
}

\begin{abstract}
Background: As the importance of the esthetic function of teeth increases, the use of esthetic restoration materials and whitening treatment are increasing. The purpose of this study was to investigate the color change of esthetic restoration materials upon using staining and whitening toothpaste.

Methods: Light curing (LC) packable composite resin, LC flowable resin, LC glass ionomer (GI), and self-curing GI specimens were colored in coffee or curry for three hours a day for seven days. After that, regular toothpaste, whitening toothpaste containing hydrogen peroxide, and whitening toothpaste containing activated charcoal were applied for three minutes three times a day for two weeks. Luminosity (L), chromaticity a (a), and chromaticity b (b) were measured using a spectrophotometer once a week.

Results: In the coffee-colored group, the change in $\mathrm{L}^{2 *} \mathrm{a}^{2 *} \mathrm{~b}^{2}\left(\mathrm{E}^{2}\right)$ with time was significant $(\mathrm{p}=0.004)$, there was no difference for different toothpaste types $(p=0.646)$, and there was significant difference $(p<0.001)$ for different esthetic restorative materials. The change of $E^{2}$ in the curry-colored group was significant only for different esthetic restorative materials $(p<0.001)$. In the coffee-colored group, the L, a, and b values of the light-curing GI showed greater change than other materials after staining and one week after whitening, turning dark, red, and yellow. In the curry-colored group, $L$ did not differ for different materials and times, and $a$ and $b$ showed the greatest difference in light-curing GI after staining and one and two weeks after whitening. Conclusion: The use of whitening toothpaste for two weeks was not different from the use of general toothpaste in the removal of staining or whitening. Since light-curing GI is the most vulnerable to coloration, it is recommended that coloring by food chromogen should be explained in advance, before using light-curing GI for teeth restoration.
\end{abstract}

Key Words: Composite resins, Dentifrices, Glass ionomer cement, Staining, Tooth bleaching agent

\section{Introduction}

With the recent improvement in economic standards, patients now demand not only functional restoration methods in dental treatment, but also esthetic restoration methods ${ }^{1)}$. As interest in bright tooth color grows, so does the need for teeth bleaching performed by dentists, and various home bleaching products are being developed.

Nevertheless, food and beverages that people eat or drink contain various sources of chromatogen, which affect the color of esthetic restorative materials. In everyday life, coffee, green tea, black tea, coke, and red wine cause discoloration of prostheses ${ }^{1)}$, with coffee staining the most ${ }^{2-5)}$, which has been claimed to be rich in chromatogen ${ }^{6}$. Recently, as the preference for coffee has increased in South Korea ${ }^{1)}$, coffee is more likely to cause changes in the color of esthetic restorative materials used for patients in South Korea. Among the foods, Indian food is known to stain the most ${ }^{6}$, with curry staining more than red pepper paste or kimchi ${ }^{7)}$. 
The degree of stain differs depending on the type of esthetic restorative material such as resin, compomer, glass ionomer (GI), and resin-modified GI (RMGI). Light curing GI is more susceptible to staining than chemical curing $\mathrm{GI}^{8)}$, and RMGI is more susceptible to staining than conventional $\mathrm{GI}^{9)}$. There is also a difference in staining depending on the composition of the resin or the weight of the filler ${ }^{10)}$, and air curing results in lower color stability compared to pressure and heat curing ${ }^{11)}$. A rough surface is easier to stain ${ }^{6}$, and the changes on the surface of esthetic restorative materials are expected to affect the degree of staining $^{12-16)}$.

While many studies have attempted to observe changes in esthetic materials by whitening agents used in home bleaching or in-office bleaching ${ }^{4,7,17-19)}$, there are few studies on the color changes of aesthetic materials in whitening toothpaste ${ }^{20,21)}$. Since whitening toothpaste is generally used with brushing, it is difficult to distinguish between the effect of the toothpaste and the effect of removing the color with physical force. This study aims to examine and compare the stain removal effect of whitening toothpaste on esthetic restorative materials in the absence of physical force such as brushing, and to investigate differences between esthetic restorative materials.

\section{Materials and Methods}

\section{Fabrication of specimens}

The used esthetic restorative materials included light curing packable composite resin (Hanfil; Handae Chemical, Jincheon, Korea), light curing flowable resin (Hanfil Flow; Handae Chemical), light curing glass ionomer cement (uniGlass Fil LC; INOD, Elmshorn, Germany), and self-curing glass ionomer cement (uniGlass Fil; INOD). Specimens were fabricated in the form of $10 \mathrm{~mm}$ in width, $24 \mathrm{~mm}$ in length, and $1 \mathrm{~mm}$ in height. For light curing, a light curing machine (Ecolight; Dmetec, Bucheon, Korea) was used as close as possible in the vertical direction for 20 seconds according to the user guidelines. For self-curing, specimens were left alone for 30 seconds to allow self-curing according to the user guidelines. A total of 72 specimens were manufactured with eight specimens for each material, and the color of the material was kept consistent at A2.

\section{Staining}

As sources of chromatogen, coffee (Kanu Columbia blend mild roast Americano; Maxim, Seoul, Korea) and curry (Ottogi beef curry; Ottogi, Anyang, Korea) were selected by referring to the previous studies on staining and considering the frequency of consumption in South Korea. Coffee and curry were diluted in distilled water according to the manufacturer's instructions. In order to keep the specimens under conditions consistent with the oral conditions, they were immersed in the source of chromatogen for a total of three hours per day, with each hour equivalent to the time of breakfast, lunch, and dinner, and soaked in distilled water at other times for seven days.

\section{Whitening}

A commercially available whitening toothpaste containing hydrogen peroxide (White Scandal Whitening toothpaste; Kumho-dp, Seoul, Korea) and a whitening toothpaste containing activated carbon (2080 Pure Black Clean Charcoal; Aekyung, Seoul, Korea) were used, as well as a toothpaste not containing whitening-related materials (2080 Signature Total Blue; Aekyung) as a control. Since it was recommended to brush the teeth for three minutes, three times a day in South Korea, the specimens were treated accordingly. In order to examine the changes in color caused by the whitening toothpaste, unlike in previous studies ${ }^{20,21)}$, only toothpaste was applied to the specimens without exerting physical force such as brushing. The specimens were treated with toothpaste for two weeks.

\section{Color measurement}

A spectrophotometer (Shimadzu UV-2450; Shimadzu, Kyoto, Japan) was used to measure luminosity (L) indicating lightness, chromaticity a (a) indicating redness or greenness, and chromaticity b (b) indicating yellowness or blueness of each specimen were measured at baseline, one week after staining, one week after whitening, and two weeks after whitening. The color of each specimen was measured repeatedly three times, and the average value was used as the representative value. After that, a 
calculation was performed using the equation, $\mathrm{E}^{2}=$ $\mathrm{L}^{2} * \mathrm{a}^{2} * \mathrm{~b}^{2}$, where $\mathrm{E}$ denoted the algebraic distance between two points in the color space.

\section{Statistical analysis}

Repeated measure ANOVA was used to measure the change over time in $\mathrm{E}^{2}$, the difference in color source, the difference between toothpastes, the difference in materials, and the interaction between them. As a result, the difference between toothpaste was not significant $(\mathrm{p}=$ 0.962 ), and there was no interaction between toothpaste and material $(\mathrm{p}=0.542)$, and between toothpaste and source of chromatogen $(\mathrm{p}=0.505)$. Therefore, in order to further analyze the difference between the esthetic restorative materials in detail considering the source of chromatogen, $\mathrm{L}, \mathrm{a}$, and $\mathrm{b}$ were analyzed using repeated measure ANOVA and ANOVA. IBM SPSS 20.0 (IBM Corp., Armonk, NY, USA) was used, and the significance level was 0.05 .

\section{Results}

1. Changes according to the type of toothpaste, type of esthetic restorative material, and time

Table 1 shows the changes in $\mathrm{E}^{2}$ for the coffee-stained group. As a result of assessing the changes according to the type of toothpaste, type of esthetic restorative material, and time in the coffee-stained group, the change over time was significant ( $\mathrm{p}=0.004)$, with no difference according to the type of toothpaste $(\mathrm{p}=0.646)$, and with a significant difference according to the type of esthetic restorative material $(p<0.001)$. There was no interaction between time and toothpaste for $\mathrm{E}^{2}$ in the coffee-stained group, but there was an interaction between time and material $(\mathrm{p}=0.044)$. Table 2 shows the changes in $\mathrm{E}^{2}$ for the currystained group. As the results of evaluation changes according to the type of toothpaste, type of esthetic restorative material, and time in the curry-stained group, none of the change over time, difference according to the type of toothpaste, and interaction between the variables was significant, but there was a significant difference according to the type of esthetic restorative material $(\mathrm{p}<0.001)$.

Table 1. $E^{2}$ Change for Different Types of Dentifrices and Esthetic Restorative Materials over Time in Coffee Staining

\begin{tabular}{clllll}
\hline Material & \multicolumn{1}{c}{ Dentifrices } & Before staining & $\begin{array}{c}1 \text { week after } \\
\text { staining }\end{array}$ & $\begin{array}{c}\text { 1 week after } \\
\text { whitening }\end{array}$ & $\begin{array}{c}2 \text { week after } \\
\text { whitening }\end{array}$ \\
\hline Self-curing GI & Normal $(\mathrm{n}=3)$ & $7,345.89 \pm 377.12$ & $6,685.13 \pm 692.77$ & $7,608.45 \pm 697.60$ & $6,334.08 \pm 990.87$ \\
& Hydorgen peroxide $(\mathrm{n}=3)$ & $6,542.76 \pm 417.99$ & $6,194.15 \pm 395.61$ & $6,784.29 \pm 340.03$ & $5,978.69 \pm 1,049.30$ \\
& Activated carbon $(\mathrm{n}=3)$ & $7,126.50 \pm 181.17$ & $6,700.87 \pm 696.92$ & $7,129.49 \pm 483.11$ & $6,357.06 \pm 1,216.00$ \\
Light-curing GI & Normal (n=3) & $5,486.77 \pm 206.60$ & $3,990.83 \pm 114.40$ & $4,483.41 \pm 119.07$ & $4,547.70 \pm 95.33$ \\
& Hydorgen peroxide $(\mathrm{n}=3)$ & $5,054.16 \pm 504.76$ & $4,184.16 \pm 50.52$ & $4,773.27 \pm 56.82$ & $5,269.37 \pm 642.86$ \\
& Activated carbon $(\mathrm{n}=3)$ & $5,654.57 \pm 315.95$ & $4,055.69 \pm 373.09$ & $4,755.58 \pm 241.16$ & $3,979.92 \pm 1,521.02$ \\
Flowable resin & Normal (n=3) & $4,453.39 \pm 340.06$ & $4,315.84 \pm 217.99$ & $4,315.65 \pm 65.12$ & $4,501.76 \pm 501.12$ \\
& Hydorgen peroxide $(\mathrm{n}=3)$ & $4,522.56 \pm 339.79$ & $4,320.98 \pm 282.44$ & $4,550.31 \pm 332.42$ & $4,411.05 \pm 154.73$ \\
& Activated carbon $(\mathrm{n}=3)$ & $4,434.97 \pm 105.08$ & $4,260.58 \pm 190.91$ & $4,270.91 \pm 127.03$ & $4,890.18 \pm 1,168.63$ \\
Packable resin & Normal (n=3) & $4,965.70 \pm 147.83$ & $4,661.34 \pm 85.23$ & $4,888.64 \pm 256.39$ & $4,295.79 \pm 1,005.59$ \\
& Hydorgen peroxide $(\mathrm{n}=3)$ & $4,811.51 \pm 129.77$ & $4,486.39 \pm 26.87$ & $4,748.81 \pm 58.09$ & $4,638.07 \pm 147.95$ \\
& Activated carbon $(\mathrm{n}=3)$ & $4,883.91 \pm 184.20$ & $4,718.11 \pm 81.87$ & $4,903.33 \pm 109.26$ & $4,825.25 \pm 57.50$ \\
\hline
\end{tabular}

Values are presented as mean \pm standard deviation.

GI: glass ionomer.

p-value: repeated-measure ANOVA.

Between-subjects effects: dentifrices, $\mathrm{p}=0.646$; esthetic restorative materials, $\mathrm{p}<0.001$; dentifrices*esthetic restorative materials, $\mathrm{p}=0.478$.

Within-subjects effects: time, $\mathrm{p}=0.004$; time*dentifrices, $\mathrm{p}=0.657$; time*esthetic restorative materials, $\mathrm{p}=0.044$; time*dentifrices* esthetic restorative materials, $\mathrm{p}=0.594$. 
EunJung Choi, et al. : Color Change of Esthetic Materials for Staining and Whitening

Table 2. $E^{2}$ Change for Different Types of Dentifrices and Esthetic Restorative Materials over Time in Curry Staining

\begin{tabular}{clllll}
\hline \multicolumn{1}{c}{ Material } & \multicolumn{1}{c}{ Dentifrices } & Before staining & $\begin{array}{c}\text { 1 week after } \\
\text { staining }\end{array}$ & $\begin{array}{c}\text { 1 week after } \\
\text { whitening }\end{array}$ & $\begin{array}{c}2 \text { week after } \\
\text { whitening }\end{array}$ \\
\hline \multirow{2}{*}{ Self-curing GI } & Normal $(\mathrm{n}=3)$ & $7,329.75 \pm 157.72$ & $7,269.02 \pm 955.06$ & $7,267.97 \pm 646.55$ & $6,719.03 \pm 1,500.59$ \\
& Hydorgen peroxide $(\mathrm{n}=3)$ & $7,244.89 \pm 32.82$ & $7,374.73 \pm 1,066.38$ & $7,109.10 \pm 548.10$ & $7,609.60 \pm 1,022.57$ \\
& Activated carbon $(\mathrm{n}=3)$ & $7,370.25 \pm 328.05$ & $7,206.34 \pm 802.71$ & $7,588.62 \pm 639.52$ & $6,855.83 \pm 2,102.13$ \\
Light-curing GI & Normal $(\mathrm{n}=3)$ & $5,771.95 \pm 528.04$ & $6,243.17 \pm 697.45$ & $6,005.53 \pm 545.28$ & $5,377.62 \pm 614.14$ \\
& Hydorgen peroxide $(\mathrm{n}=3)$ & $5,610.42 \pm 59.46$ & $5,929.07 \pm 65.49$ & $5,750.57 \pm 50.19$ & $5,502.65 \pm 343.07$ \\
& Activated carbon $(\mathrm{n}=3)$ & $5,013.69 \pm 427.41$ & $5,553.64 \pm 656.73$ & $5,614.25 \pm 502.65$ & $4,958.04 \pm 1,179.72$ \\
Flowable resin & Normal $(\mathrm{n}=3)$ & $4,380.23 \pm 177.73$ & $4,403.02 \pm 64.42$ & $4,340.34 \pm 66.30$ & $4,356.72 \pm 38.69$ \\
& Hydorgen peroxide $(\mathrm{n}=3)$ & $4,437.20 \pm 110.53$ & $4,484.52 \pm 132.12$ & $4,493.20 \pm 108.50$ & $4,761.40 \pm 538.28$ \\
& Activated carbon $(\mathrm{n}=3)$ & $4,415.84 \pm 112.95$ & $4,418.54 \pm 142.17$ & $4,433.34 \pm 11.15$ & $5,093.18 \pm 1,254.44$ \\
Packable resin & Normal (n=3) & $4,729.40 \pm 78.07$ & $4,789.15 \pm 196.60$ & $4,615.29 \pm 43.43$ & $4,240.25 \pm 703.19$ \\
& Hydorgen peroxide $(\mathrm{n}=3)$ & $4,849.16 \pm 76.43$ & $5,073.11 \pm 151.20$ & $5,131.63 \pm 203.53$ & $4,696.47 \pm 288.37$ \\
& Activated carbon $(\mathrm{n}=3)$ & $4,953.64 \pm 27.49$ & $5,097.41 \pm 79.18$ & $4,907.49 \pm 217.40$ & $4,914.43 \pm 227.27$ \\
\hline
\end{tabular}

Values are presented as mean \pm standard deviation.

GI: glass ionomer.

p-value: repeated-measure ANOVA.

Between-subjects effects: dentifrices, $\mathrm{p}=0.733$; esthetic restorative materials, $\mathrm{p}<0.001$; dentifrices*esthetic restorative materials, $\mathrm{p}=0.684$.

Within-subjects effects: time, $\mathrm{p}=0.235$; time*dentifrices, $\mathrm{p}=0.541$; time*esthetic restorative materials, $\mathrm{p}=0.292$; time*dentifrices* esthetic restorative materials, $\mathrm{p}=0.988$.

Table 3. Luminosity (L), Chromaticity a (a), and Chromaticity b (b) Changes for Different Esthetic Restorative Materials over Time in Coffee Staining

\begin{tabular}{|c|c|c|c|c|c|c|}
\hline $\begin{array}{c}\text { Color } \\
\text { measurement }\end{array}$ & Difference & Self-curing GI & Light-curing GI & Flowable resin & Packable resin & p-value \\
\hline \multirow[t]{4}{*}{$\mathrm{L}$} & Before-1 week after staining & $3.10 \pm 2.58^{\mathrm{a}}$ & $13.14 \pm 5.21^{\mathrm{b}}$ & $1.63 \pm 0.80^{\mathrm{a}}$ & $2.09 \pm 0.89^{\mathrm{a}}$ & $<0.001$ \\
\hline & Before-1 week after whitening & $-0.96 \pm 3.22^{\mathrm{a}}$ & $6.32 \pm 4.35^{\mathrm{b}}$ & $0.67 \pm 1.45^{\mathrm{a}}$ & $-0.07 \pm 1.65^{\mathrm{a}}$ & $<0.001$ \\
\hline & Before-2 weeks after whitening & $4.32 \pm 7.97$ & $6.63 \pm 11.51$ & $-0.95 \pm 4.29$ & $1.80 \pm 5.05$ & 0.209 \\
\hline & p-value & 0.560 & 0.032 & 0.166 & 0.208 & \\
\hline \multirow[t]{4}{*}{$\mathrm{a}$} & Before-1 week after staining & $0.15 \pm 0.24^{\mathrm{a}}$ & $-4.51 \pm 0.87^{\mathrm{b}}$ & $-0.86 \pm 0.56^{\mathrm{c}}$ & $-1.30 \pm 0.20^{\mathrm{c}}$ & $<0.001$ \\
\hline & Before-1 week after whitening & $-0.04 \pm 0.18^{\mathrm{a}}$ & $-2.17 \pm 0.51^{\mathrm{b}}$ & $-0.79 \pm 0.35^{\mathrm{c}}$ & $-1.22 \pm 0.24^{\mathrm{c}}$ & $<0.001$ \\
\hline & Before- 2 weeks after whitening & $-0.27 \pm 0.68^{\mathrm{a}}$ & $-1.35 \pm 1.15^{\mathrm{b}}$ & $-0.68 \pm 0.37^{\mathrm{ab}}$ & $-1.57 \pm 0.49^{\mathrm{b}}$ & 0.002 \\
\hline & p-value & 0.115 & $<0.001$ & 0.292 & 0.113 & \\
\hline \multirow[t]{4}{*}{$\mathrm{b}$} & Before- 1 week after staining & $-1.61 \pm 1.93^{\mathrm{a}}$ & $-14.78 \pm 1.67^{\mathrm{b}}$ & $-2.72 \pm 1.63^{\mathrm{a}}$ & $-0.95 \pm 1.23^{\mathrm{a}}$ & $<0.001$ \\
\hline & Before-1 week after whitening & $-0.48 \pm 2.59^{\mathrm{a}}$ & $-7.87 \pm 1.74^{\mathrm{b}}$ & $0.03 \pm 1.37^{\mathrm{ac}}$ & $2.27 \pm 1.18^{\mathrm{c}}$ & $<0.001$ \\
\hline & Before-2 weeks after whitening & $0.04 \pm 2.61^{\mathrm{a}}$ & $-4.37 \pm 1.73^{\mathrm{b}}$ & $0.77 \pm 0.97^{\mathrm{a}}$ & $3.63 \pm 1.33^{\mathrm{c}}$ & $<0.001$ \\
\hline & p-value & 0.235 & $<0.001$ & $<0.001$ & $<0.001$ & \\
\hline
\end{tabular}

Values are presented as mean \pm standard deviation.

GI: glass ionomer.

p-value: repeated measure ANOVA.

${ }_{\mathrm{a}, \mathrm{b}, \mathrm{c}}$ Tukey post-hoc analysis.

\section{Difference between esthetic restorative materials in staining and whitening}

Since there was almost no difference in whitening according to the type of toothpaste, the differences in L, a, and $\mathrm{b}$ were assessed for each esthetic restorative material. In the coffee-stained group, the $\mathrm{L}$ and a values were significant in light curing GI, and the $b$ value was significant in light curing GI, flowable resin, and packable resin (Table 3 ). The change in all of the $\mathrm{L}$, $\mathrm{a}$, and $\mathrm{b}$ was the most prominent in light curing GI one week after staining and one week after whitening, compared to other materials, and the color turned darker, redder, and 
Table 4. Luminosity (L), Chromaticity a (a), and Chromaticity b (b) Changes for Different Esthetic Restorative Materials over Time in Curry Staining

\begin{tabular}{|c|c|c|c|c|c|c|}
\hline & Difference & Self-curing GI & Light-curing GI & Flowable resin & Packable resin & p-value \\
\hline \multirow[t]{4}{*}{$\mathrm{L}$} & Before-1 week after staining & $0.57 \pm 4.11$ & $1.06 \pm 2.40$ & $1.09 \pm 0.72$ & $0.92 \pm 0.67$ & 0.966 \\
\hline & Before-1 week after whitening & $-0.09 \pm 2.85$ & $-1.32 \pm 1.51$ & $-0.10 \pm 0.94$ & $-0.36 \pm 1.72$ & 0.471 \\
\hline & Before-2 weeks after whitening & $-0.09 \pm 0.67$ & $0.90 \pm 0.40$ & $-0.22 \pm 0.26$ & $-0.67 \pm 0.43$ & 0.330 \\
\hline & p-value & 0.724 & 0.180 & 0.106 & 0.213 & \\
\hline \multirow[t]{4}{*}{$\mathrm{a}$} & Before-1 week after staining & $0.39 \pm 0.46^{\mathrm{a}}$ & $4.41 \pm 1.06^{\mathrm{b}}$ & $2.38 \pm 0.34^{\mathrm{c}}$ & $2.28 \pm 0.45^{\mathrm{c}}$ & $<0.001$ \\
\hline & Before-1 week after whitening & $-0.20 \pm 0.09^{\mathrm{a}}$ & $1.89 \pm 0.67^{\mathrm{b}}$ & $0.02 \pm 0.38^{\mathrm{a}}$ & $-0.12 \pm 0.44^{\mathrm{a}}$ & $<0.001$ \\
\hline & Before-2 weeks after whitening & $-0.09 \pm 0.67^{\mathrm{a}}$ & $0.90 \pm 0.40^{\mathrm{b}}$ & $-0.22 \pm 0.26^{\mathrm{a}}$ & $-0.67 \pm 0.43^{\mathrm{a}}$ & $<0.001$ \\
\hline & p-value & 0.013 & $<0.001$ & $<0.001$ & $<0.001$ & \\
\hline \multirow[t]{4}{*}{$\mathrm{b}$} & Before-1 week after staining & $-2.33 \pm 1.79^{\mathrm{a}}$ & $-18.40 \pm 4.76^{\mathrm{b}}$ & $-7.55 \pm 2.03^{\mathrm{c}}$ & $-8.17 \pm 1.44^{\mathrm{c}}$ & $<0.001$ \\
\hline & Before-1 week after whitening & $0.96 \pm 0.98^{\mathrm{a}}$ & $-6.75 \pm 2.87^{\mathrm{b}}$ & $-0.06 \pm 1.43^{\mathrm{a}}$ & $0.54 \pm 1.51^{\mathrm{a}}$ & $<0.001$ \\
\hline & Before-2 weeks after whitening & $1.74 \pm 1.04^{\mathrm{ac}}$ & $-3.53 \pm 1.35^{\mathrm{b}}$ & $0.42 \pm 1.24^{\mathrm{a}}$ & $2.71 \pm 1.71^{\mathrm{c}}$ & $<0.001$ \\
\hline & p-value & $<0.001$ & $<0.001$ & $<0.001$ & 0.001 & \\
\hline
\end{tabular}

Values are presented as mean \pm standard deviation.

GI: glass ionomer.

p-value: repeated measure ANOVA.

${ }_{\mathrm{a}, \mathrm{b}, \mathrm{c}}$ Tukey post-hoc analysis.

yellower (Table 3). In the curry-stained group, no change was observed in the $\mathrm{L}$ value over time or according to the type of material, but the $a$ and $b$ values showed $a$ difference over time and according to the type of material (Table 4). As for the a value, and a and b values show the most prominent difference in light curing GI one week after staining, one week after whitening, and two weeks after whitening. The color turned redder and yellower compared to the baseline.

\section{Discussion}

This study attempted to investigate the changes in color caused by staining and whitening with different esthetic restorative materials and toothpastes. As a result, the color of light curing GI changed more by staining or whitening, compared to that of resin or chemical curing GI. The findings of previous studies on the color difference due to staining or whitening (bleaching) of esthetic restorative materials suggesting that GI showed a more severe color change than resin were in line with the results of this study. Kim et al. ${ }^{1)}$ reported that the color change of RMGI and GI was greater than that of resin after bleaching with carbamide peroxide, and that the resin showed no significant difference in the coffee-stained group while RMGI and GI showed a significant difference in color.
Lee and $\mathrm{Kim}^{8)}$ argued that light curing GI was more susceptible to staining than chemical curing GI, which was in line with the results of this study demonstrating a more prominent change in light curing GI. In particular, whitened GI was reported to have more cracks or pits on the surface than resin, showing an increase in stain susceptibility after bleaching ${ }^{12-17)}$. However, there was also a study reporting that the color returned to the color before whitening two weeks after stopping bleaching ${ }^{12)}$. The resin was also susceptible to staining ${ }^{7)}$ and whitened resin became more susceptible to staining ${ }^{15)}$, but the change in color was not significant enough to necessitate resin replacement after bleaching ${ }^{22)}$. In many of the cited studies, a staining experiment was performed after bleaching an esthetic restorative material, but this study performed staining prior to observing whether the stain was removed by the application of whitening toothpaste.

Recently, the whitening toothpastes containing about $3 \%$ hydrogen peroxide have been sold to meet the demand for brightening the color of teeth. Even though the concentration of hydrogen peroxide contained in whitening toothpaste is low, some users have reported adverse effects such as tooth hypersensitivity, gingival irritation, and decalcification. Activated carbon can adsorb contaminants, and it has been used as a folk remedy to clean teeth. Recently, companies are selling whitening toothpaste 
containing activated carbon. However, as there has been no research on whether toothpaste containing activated carbon is effective for whitening reported, this study included the whitening toothpaste in the experiment. In the results of this study, there was no difference according to the type of toothpaste (regular toothpaste, whitening toothpaste containing hydrogen peroxide, and toothpaste containing activated carbon) during the two-week whitening experiment period, with no increase or decrease in the value of $\mathrm{E}^{2}$. The results of other studies also reported no consistent increase or decrease during the whitening or staining period ${ }^{7,21,23)}$. Nevertheless, previous studies in which teeth were brushed with whitening toothpaste reported that the color of teeth became lighter, showing different results from those of this study ${ }^{20,21)}$. Since the lightness was reported to increase with the use of more abrasive toothpaste ${ }^{21)}$, and tooth brushing with general toothpaste was also found to be effective in removing stains from esthetic restorative materials ${ }^{23)}$, the difference could have been caused by the absence of brushing in this study. Furthermore, a study using whitening toothpaste reported its effectiveness after four weeks $^{20)}$, and a longer-term study seemed necessary to assess the difference between whitening toothpaste and general toothpaste as this study only used whitening toothpaste for two weeks.

\section{Notes}

\section{Conflict of interest}

No potential conflict of interest relevant to this article was reported.

\section{Author contributions}

Conceptualization: HyeonSoo Jang, YeLim Seo, YoungJu Kim, GaYoung Lee, YouLim Kim, and Soo-Jeong Hwang. Data acquisition: EunJung Choi, HyeonSoo Jang, YeLim Seo, YoungJu Kim, GaYoung Lee, and YouLim Kim. Statistical Analysis: Soo-Jeong Hwang. Supervision: EunJung Choi and Soo-Jeong Hwang. Writing-original draft: EunJung Choi, HyeonSoo Jang, YeLim Seo, YoungJu Kim, GaYoung Lee, YouLim Kim, and Soo-Jeong Hwang. Writing-review \& editing: Soo-Jeong Hwang.

\section{ORCID}

EunJung Choi, https://orcid.org/0000-0002-5020-3055

HyeonSoo Jang, https://orcid.org/0000-0003-1039-4982

YeLim Seo, https://orcid.org/0000-0002-3166-7823

YoungJu Kim, https://orcid.org/0000-0003-2968-4410

GaYoung Lee, https://orcid.org/0000-0003-1887-5828

YouLim Kim, https://orcid.org/0000-0001-9424-6877

Soo-Jeong Hwang, https://orcid.org/0000-0003-4725-1512

\section{References}

1. Kim SH, Choi HS, Roh JY, Kim KM: The effect of $15 \%$ carbamide peroxide on the surface roughness and staining of esthetic restoratives. J Dent Hyg Sci 13: 165-173, 2013.

2. Poggio C, Ceci M, Beltrami R, Mirando M, Wassim J, Colombo M: Color stability of esthetic restorative materials: a spectrophotometric analysis. Acta Biomater Odontol Scand 2: 95-101, 2016. https://doi.org/10.1080/23337931.2016.1217416

3. Ceci M, Viola M, Rattalino D, Beltrami R, Colombo M, Poggio C: Discoloration of different esthetic restorative materials: a spectrophotometric evaluation. Eur J Dent 11: 149-156, 2017. https://doi.org/10.4103/ejd.ejd_313_16

4. Guler AU, Yilmaz F, Kulunk T, Guler E, Kurt S: Effects of different drinks on stainability of resin composite provisional restorative materials. J Prosthet Dent 94: 118-124, 2005. https://doi.org/10.1016/j.prosdent.2005.05.004

5. Lee W, Jung JE, Jung KH, et al.: The translucent and color change of nanofilled composite resin according to resin shades and staining solutions. Korean J Dent Mater 41: 121-128, 2014.

6. Padiyar N, Kaurani P: Colour stability: an important physical property of esthetic restorative materials. Int J Clin Dent Sci 1: 81-84, 2010.

7. Choi EJ, Moon SH, Mun SR, et al.: Color change of food staining and bleaching on composite resin. J Dent Hyg Sci 12: 477-485, 2012.

8. Lee DH, Kim S: A study on the staining of glass ionomer cement. J Korean Acad Pediatr Dent 24: 58-64, 1997.

9. Bagheri R, Burrow MF, Tyas M: Influence of food-simulating solutions and surface finish on susceptibility to staining of aesthetic restorative materials. J Dent 33: 389-398, 2005. 
https://doi.org/10.1016/j.jdent.2004.10.018

10. Ardu S, Braut V, Gutemberg D, Krejci I, Dietschi D, Feilzer AJ: A long-term laboratory test on staining susceptibility of esthetic composite resin materials. Quintessence Int 41: 695-702, 2010.

11. Park SH, Cho IH: A study on the color stability of temporary resins according to polymerizing methods and staining. $\mathrm{J}$ Dent Rehab App Sci 16: 1-11, 2000.

12. Li Q, Yu H, Wang Y: Colour and surface analysis of carbamide peroxide bleaching effects on the dental restorative materials in situ. J Dent 37: 348-356, 2009. https://doi.org/10.1016/j.jdent.2009.01.003

13. Yu H, Li Q, Hussain M, Wang Y: Effects of bleaching gels on the surface microhardness of tooth-colored restorative materials in situ. J Dent 36: 261-267, 2008. https://doi.org/10.1016/j.jdent.2008.01.008

14. Basting RT, Fernandéz Y Fernandez C, Ambrosano GM, de Campos IT: Effects of a 10\% carbamide peroxide bleaching agent on roughness and microhardness of packable composite resins. J Esthet Restor Dent 17: 256-262; discussion 263, 2005.

https://doi.org/10.1111/j.1708-8240.2005.tb00124.x

15. Yu H, Pan X, Lin Y, Li Q, Hussain M, Wang Y: Effects of carbamide peroxide on the staining susceptibility of toothcolored restorative materials. Oper Dent 34: 72-82, 2009. https://doi.org/10.2341/08-42

16. de A Silva MF, Davies RM, Stewart B, et al.: Effect of whitening gels on the surface roughness of restorative materials in situ. Dent Mater 22: 919-924, 2006. https://doi.org/10.1016/j.dental.2005.11.029

17. Yu H, Zhang CY, Cheng SL, Cheng H: Effects of bleaching agents on dental restorative materials: a review of the literature and recommendation to dental practitioners and researchers. J Dent Sci 10: 345-351, 2015.

https://doi.org/10.1016/j.jds.2014.08.005

18. Tinastepe N, Malkondu O, Iscan I, Kazazoglu E: Effect of home and over the contour bleaching on stainability of $\mathrm{CAD} / \mathrm{CAM}$ esthetic restorative materials. J Esthet Restor Dent 33: 303-313, 2021. https://doi.org/10.1111/jerd.12604

19. Kimyai S, Ghavami Lahij Y, Daneshpooy M, Navimipour EJ, Oskoee PA: Effect of bleaching with $15 \%$ carbamide peroxide on flexural strength of three resin-based restorative materials. Front Dent 17: 27, 2020. https://doi.org/10.18502/fid.v17i27.4651

20. Roopa KB, Basappa N, Prabhakar AR, Raju OS, Lamba G: Effect of whitening dentifrice on micro hardness, colour stability and surface roughness of aesthetic restorative materials. J Clin Diagn Res 10: ZC06-ZC11, 2016. https://doi.org/10.7860/JCDR/2016/15700.7350

21. Sumendap IB, Herda E, Eriwati YK: Effect of whitening toothpaste on the discoloration level of stained conventional glass ionomer cement. J Phys Conf Ser 1073: 062013, 2018. http://doi.org/10.1088/1742-6596/1073/6/062013

22. Villalta P, Lu H, Okte Z, Garcia-Godoy F, Powers JM: Effects of staining and bleaching on color change of dental composite resins. J Prosthet Dent 95: 137-142, 2006. https://doi.org/10.1016/j.prosdent.2005.11.019

23. Bezgin T, Özer L, Tulga Öz F, Özkan P: Effect of toothbrushing on color changes of esthetic restorative materials. J Esthet Restor Dent 27 Suppl 1: S65-S73, 2015. https://doi.org/10.1111/jerd.12136 